\title{
Research on the Performance Appraisal of Human Resources in Public Institutions
}

\author{
Yan-yan Huang* \\ Shandong Provincial Territorial Space Ecological Restoration Center, Jinan 250014, Shandong Province, China \\ *Corresponding author: Yan-yan Huang, 1062961387@qq.com
}

\begin{abstract}
Under the background of economic globalization, the rapid development of the society and the intricate changes also require a leap in the economy and management level. For state-owned institutions, it is of great significance to maximize the enthusiasm of employees and managers as well as establish a scientific and efficient performance appraisal mechanism. This paper analyzes the existing problems and deficiencies of performance appraisal in public institutions and puts forward corresponding optimization countermeasures and plans.
\end{abstract}

Keywords: Performance appraisal; Human resources; Public institutions

Publication date: December 2021; Online publication: December 31, 2021

\section{Introduction}

In state-owned enterprise management, the most important thing is its human resource management. In regard to the soft power of an institution, the core lies in the design of the human resource management at the top management, including human resource management mechanism, institution performance, and compensation system design. Whether the top-level management design can attract talents or build a strong core team is related to the future fate and success or failure of the institution. Performance management is one of the most difficult tasks in human resource management. With the development and change of the operating environment, public institutions need to carry out accurate cost accounting in daily operations, establish quantifiable performance management standards, and carry out comprehensive performance appraisal. At present, the management of public institutions is not in place, largely due to the lack of a comprehensive performance management system. By linking business data with performance management, making payment related to work performance, and adopting a comprehensive incentive mechanism, only then it is possible to spur the backward and encourage advancement, thus achieving the management goals of public institutions.

\section{Major problems in the appraisal of public institutions}

\subsection{Unsound performance appraisal indicators and unreasonable personnel allocation}

The unsound performance appraisal indicators and unreasonable personnel allocation affect the scientific and reasonable performance appraisal. The appraisal indicators and weights are inaccurate, the appraisal indicators of public institutions are not closely related to the work objectives of the center and the job responsibilities of employees, the quantitative appraisal indicators do not objectively reflect the actual work achievements of the staffs, and the appraisal is superficial and formalized. The performance appraisal indicators, the institution work goals, and the job responsibilities of employees are not effective and unified; the job responsibilities that are decomposed according to the central work objectives of the institution are 
not implemented for every employee; the strategic objectives of the institution are not fully analyzed; the job responsibilities are shallow, vague, and not fully implemented; the performance appraisal indicators cannot be clearly and effectively extracted; the strategic objectives remain, the work is not implemented, and the goals and work are separated. The evaluation basis of employees at all levels, the appraisal results, and the basis of talent selection are not accurate; in addition, it is difficult to motivate the staffs to work. The appraisal indicators remain unchanged over the years, and it is difficult to advance with the times.

In state-owned institutions, there is no match-up according to skills, post requirements, and qualifications of staffs, resulting in the inconsistency between posts and talents. In particular, the employment for important positions is designated by the leader, and the will of the leader affects the subjective allocation of personnel. This unreasonable employment mechanism hinders the value of some personnel, resulting in a waste of human resources. The comprehensive quality of employees in public institutions is uneven; some of them have relatively poor skills although equipped with high qualifications and positions, thus affecting the work efficiency in public institutions.

\subsection{Relatively backward appraisal concept}

Most public institutions still use the traditional evaluation standard - virtue, ability, diligence, performance, and integrity. With the continuously advancement of the reform and opening-up, more and more foreign companies are entering China, and the number of joint ventures are increasing day by day. The management methods of foreign enterprises, such as Amoeba, OKR, KPI, and other business philosophies, are in sharp contrast with those of state-owned enterprises; this has a strong impact on state-owned enterprises ${ }^{[1]}$. Some banks have applied the Heisenberg and American-style job evaluation systems. Major reform and adjustment should be made in terms of performance and salary. Most public institutions monopolize the industry, and the project tasks are allocated by the state, so the regulatory effect of the market competition has little influence on them. As a result, they are relatively complacent, and their management concepts as well as methods are obviously behind the market. In order for public institutions to walk in the forefront of the times, it is necessary to carry out new human resource management methods. At present, the management of state-owned institutions is unable to keep up with the market competition, with declining economic benefits. It is urgent to improve the management, give play to their own advantages, and improve the market competitiveness.

\subsection{Ineffective application of the results of performance appraisal and imperfect appraisal process}

The results of performance appraisal are not applied effectively, and the appraisal process of public institutions is imperfect because the appraisal results are not accurate. For example, the personnel in public institutions are qualified except those who violate the law and are dealt with by the court. There are workers who take half a year's maternity leave at home and still perform well at the end of the year. Due to the embarrassment and helplessness of many appraisal indicators, the appraisal results have little reference value, so the management personnel in public institutions do not pay attention to the appraisal results. After evaluation and scoring, there is no timely analysis and feedback on the evaluation results, no performance interview and communication, let alone a performance improvement plan. The incentive mechanism needs to be optimized, and the appraisal result cannot play a real role. The appraisal result is not related to the employee's salary, qualification, training, reward, and punishment; the performance does not correspond to the salary, the salary treatment is unfair, the incentive mechanism is lost, and personnel do not act or make progress, which greatly affects the development interest and development speed of the institution. 


\section{Improvement direction and countermeasures of performance appraisal in public institutions}

\subsection{Improve the appraisal indicators and optimize the employment mechanism}

Based on the overall strategic objectives and the task objectives of the institution, the overall objectives of the annual work of the institution (management objectives, production objectives, financial objectives, human resources objectives, etc.) are decomposed from the time dimension to half a year, month, and day, in order to form a target plan. From the spatial dimension, the tasks of each department (name, content, emergency level, task completion date, personnel cooperation, expected results, etc.) are decomposed to each employee. The employee's work objectives (appraisal indicators) are refined based on his or her job responsibilities and qualification requirements. It is necessary to attach importance to the daily work of employees, pay attention to the combination of performance and normal work, sort out job responsibilities and tasks from the source, implement performance indicators reflecting departments and employees, as well as avoid one-sided emphasis on performance while neglecting daily work. The e-HR system should be implemented for the in-depth analysis of appraisal data, so as to provide clear data analysis for employees' objective evaluation and daily work management.

The allocation of leaders in public institutions should first be scientific and reasonable. It should also be honest and clean, with strong governance ability as well as diligent cadre selection and appointment to the leading position of institutions. Officials should be encouraged to start their own businesses with the right guidance for employment; officials and employees should be guided to set their original aspiration on action and overcome various difficulties as well as challenges with satisfactory results. At present, the technical personnel employment system is still facing theoretical and practical difficulties; therefore, the technical personnel employment system should be perfected. In theory, most public institutions have put forward the principle of "meritocracy, talent, promotion and demotion, entry and exit," but in practice, it is only formalized in the policy concept and slogan as it is difficult to implement. The administrative power interferes too much, and the protected rights and interests of technical personnel as well as their rights to speak are weak. Administration should be streamlined, power should be delegated, administrative intervention should be reduced, and the voice of technical personnel should be improved; the concept should be changed once for all. From the actual point of view, the employment related system should be established and improved, while the personnel-qualification employment and personnel post-employment mechanism should be adopted.

\subsection{Improve the appraisal methods and strengthen the feedback on the appraisal results}

The majority of institutions are still using the same kind of appraisal method (virtue, ability, diligence, performance, and integrity) for staffs. The appraisal indicators and weight have difficulty in reflecting the difference between the degree of work involvement and contribution, thus weakening the significance of the performance appraisal itself. In regard to the quantitative management originating from the United States, starting from the management objectives and the use of scientific and quantifiable management means as well as management tools to design the organizational system and establish standard management means for specific work, quantifiable appraisal indicators ensure a practical and operable human resource performance appraisal. It is imperative to adopt more advanced performance appraisal methods, adjust and improve the performance appraisal system of institutions, departments, and individuals, as well as ensure each indicator is refined, quantifiable, more targeted, and measurable. KPI and management by objectives, which have been adopted by a few public institutions, can better guide employees to concentrate on key business areas, highlight the key points of appraisal, and effectively reflect the development status of departments and employees. They should be actively used for reference, promotion, and application. Continuously exploring and improving performance appraisal methods, further improving appraisal 
techniques and means, so as to increase appraisal efficiency and accuracy, improving performance appraisal results, and promoting the personal growth of employees have huge incentive roles. Taking Shandong Provincial Territorial Space Ecological Restoration Center as an example, the current performance appraisal method has five grades: excellent, good, qualified, basically qualified, and unqualified; the weight of its evaluation score is as follows: the mass evaluation score accounts for $30 \%$, the evaluation score of the leader-in-charge accounts for 30\%, and the evaluation score of the leaders accounts for $40 \%$. This method is simple and easy to operate however, it lacks the guidance of in-depth appraisal indicators and describes the evaluation criteria in an abstract and vague way. As a result, different people have different evaluation standards, and superficial work may occur. First, the use of the target decomposition method is to decompose a center's overall task objectives (Figure 1).

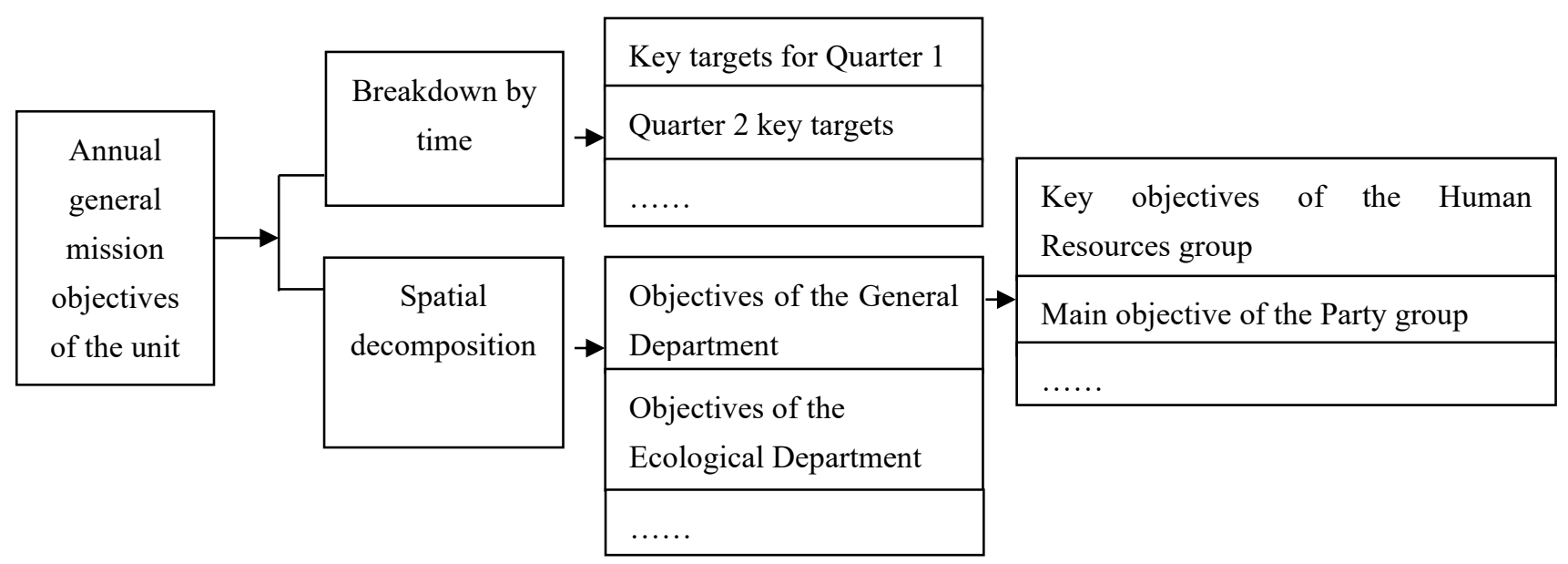

Figure 1. Decomposition of the overall task objectives

Second, taking the Human Resource group of the General Affairs Department as an example, according to the decomposition of task objectives, the personnel KPI appraisal indicators are extracted as shown in Table $1^{[2]}$.

Table 1. Appraisal indicators based on the decomposition of task objectives

\begin{tabular}{|c|c|c|c|}
\hline Position title & Appraisal indicators & Specific description & Weight \\
\hline \multirow{7}{*}{$\begin{array}{l}\text { HR team } \\
\text { leader }\end{array}$} & Department plan & $\begin{array}{l}\text { Whether the plan is reasonable, whether the plan is implemented on } \\
\text { time }\end{array}$ & $20 \%$ \\
\hline & Recruitment & Recruitment plan implementation rate & $15 \%$ \\
\hline & Training work plan & Training implementation rate & $15 \%$ \\
\hline & Performance appraisal & Whether to organize performance appraisal as planned & $10 \%$ \\
\hline & Compensation and benefits & Whether the compensation work starts on time and error rate & $10 \%$ \\
\hline & Quality evaluation & Professional dedication, service awareness, etc. & $10 \%$ \\
\hline & Satisfaction evaluation & $\begin{array}{l}\text { The overall satisfaction of completing the task (from the } \\
\text { evaluations of the masses and the leaders) }\end{array}$ & $20 \%$ \\
\hline
\end{tabular}

(Continued on the next page) 


\begin{tabular}{|c|c|c|c|}
\hline Position title & Appraisal indicators & Specific description & Weight \\
\hline \multirow{4}{*}{ Staff } & Work progress & $\begin{array}{l}\text { The tasks assigned by the staff have been completed according to } \\
\text { the department plan }\end{array}$ & $35 \%$ \\
\hline & Work quality & $\begin{array}{l}\text { The tasks assigned have been completed according to the } \\
\text { department plan }\end{array}$ & $35 \%$ \\
\hline & Quality evaluation & Professional dedication, service awareness, etc. & $10 \%$ \\
\hline & Satisfaction evaluation & $\begin{array}{l}\text { The overall satisfaction of completing the task (from the } \\
\text { evaluations of the masses and the leaders) }\end{array}$ & $20 \%$ \\
\hline
\end{tabular}

Third, the feedback on appraisal results is strengthened. The managers under the leadership in charge shall conduct face-to-face performance appraisal interviews with subordinates, with timely communication and correction of errors. Line managers at all levels shall help subordinates improve their work performance. Employees need feedback about their performances. Performance can be improved with feedback, and feedback helps employees to know what to do and how well they are meeting their own goals. It shows that others are interested in what they are doing. Assuming that performance is satisfactory, feedback enhances an employee's self-image and feeling of competence. In general, performance feedback improves attitude as well as performance.

\subsection{Attach importance to the appraisal results and optimize incentive mechanisms}

Performance-related pay is directly related to an individual's performance. It is a common application of performance appraisal. In order to enhance the incentive effect of compensation, employee compensation is linked to performance, salary adjustment is determined by performance results, and annual performance appraisal is linked to salary rank adjustment. Performance appraisal is related to job adjustment and provides reference for job change. If an employee has outstanding performance in career planning, he or she can be promoted to assume more responsibilities in a certain aspect. Performance appraisal is related to labor relations, while annual appraisal result is related to labor contract renewal. If unqualified, the contract will not be renewed. Performance appraisal is connected to employee training, providing more training opportunities for employees with excellent performance appraisal results and targeted training for employees with poor performance appraisal results. Performance appraisal is related to qualifications, and appraisal results are also related to qualifications. With the development and progress of the industry itself, public institutions have put forward higher professional standards in cost control, fund operation, project development, and other aspects as well as have constantly put in effort to improve the knowledge and skill requirements of relevant employees. With the continuous enrichment of job responsibilities and the improvement of personnel quality, it is difficult for some personnel to match their skills and qualifications. Therefore, it is necessary to give full play to the incentive role of performance appraisal and link the appraisal results with employment in the context of qualification. For staffs with high qualifications but have poor skills and unable to achieve the job responsibilities, necessary adjustments should be made in time, such as the employment of a lower qualification. Institutions should give full play to the incentive role of performance appraisal, stimulate the enthusiasm, initiative, and creativity of employees, create a good working atmosphere for innovation and ambition, so as to improve the working environment, attract and retain talents, as well as achieve a healthy development.

In regard to individual work behavior, manifestation, achievement, and personal performance alignment; the docking of department team performance and individual performance; the docking of the entire institution (multiple departments team performance) and individual performance, performance 
appraisal makes managers and employees truly stand on the same boat, sharing risks and benefits. The relationship between managers and employees is no longer a simple relationship between the management and the managed, but a performance partner, which promotes the integration of the interests of the public institution and its employees as well as the consistency of the development goals of the institution and its employees. This would promote the institution and its employees to reach a community of interests, and ultimately achieve a win-win situation for the interests of both the institution and its employees.

\section{Conclusion}

In order to perfect the appraisal system, it is necessary to perfect the appraisal indicators, improve the appraisal method, pay attention to the appraisal results, optimize the incentive mechanism, advance with the times, and learn from others. Performance appraisal should be taken as an effective means of performance improvement, the performance goal orientation of the institution and the staffs should be improved, the management level and management ability should be enhanced, and employees should be exposed to the direction of struggle as well as encouraged to develop together with the institution, so as to finally realize a win-win situation for the institution and the staffs.

\section{Disclosure statement}

The author declares that there is no conflict of interest.

\section{References}

[1] Cai Q, 2020, Performance Appraisal of Human Resource Management in State-Owned Enterprises. On Business in China, 2020(10): 2.

[2] He Q, 2014, Overall Solution of Performance Appraisal and Salary Incentive, China Legal Publishing House. 